\title{
Polish Society Celebrates its 75th Year
}

This year's biennial Congress of the Polish Physical Society (the 33rd) in Wroclaw on 18-21 September attracted some 500 participants, not only because it marked the Society's 75th Anniversary but also because it gave an excellent opportunity for many to learn more about a region that has a long and proud tradition in science. Eight Nobel laureates (including two in physics) worked at some stage in their careers in Wroclaw, where physics is based at the University of Wroclaw, the Technical University, the Polish Academy of Science's Institute for
Low Temperatures and Structural Research (see below) and its daughter laboratory, the International Laboratory of High Magnetic Fields and Low Temperatures. Research in biophysics is also carried out in two pedagogical academies.

As befits such an occasion, two Nobel laureates (K. von Klitzing and K.A. Miller) gave plenary lectures and many distinguished Polish physicists spoke on various aspects of physics, including the history of physics in Wroclaw in the early years after Poland regained its western territories 50

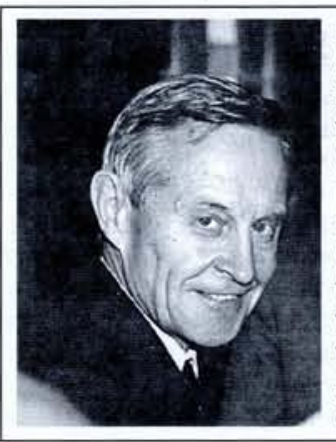

Ryszard Sosnowski was awarded the Marian Smoluchowski Medal - the Polish Physical Society's highest distinction - at the Society's 33rd Congress for his contributions to high-energy particle physics. He has worked at the Institute for Nuclear Studies, Warsaw, since graduating in physics from Warsaw University in 1955. His study, in collaboration with CERN, of multiple hadron production in collisions began in the early 1960 s and led to analyses of different aspects of the process using data from CERN the JINR (Dubna) and Fermilab in the US. In 1964, he co-authored the paper which introduced the so-called "principal axis" analysis that is now widely used to describe multiple hadron production, albeit under the term "thrust". Professor Sosnowski presently participates in the DELPHI collaboration at CERN's LEP collider.

\section{Bilateral Cooperation Now More Important}

Szymon Bauch from the Institute of Physics of the Polish Academy of Sciences, Warsaw, and a member of the Polish Physical Society's Committee for International Cooperation reports on bilateral cooperation agreements.

The Polish Physical Society (PPS) has a long tradition in a bilateral contacts with other national physical societies. However, prior to 1989 these contacts were rather formal and limited to societies based in the eastern bloc. The only exception was an agreement with the Federal Republic of Germany. PPS activities had to be approved by the Polish Academy of Sciences (PAS, a governmental institution) so many possibilities, apart from the exchange of physicists which was financed on the Polish side by the PAS, were not developed.

Experience over the last six years has convinced the PPS that bilateral cooperation agreements between national societies have become more important in today's quite different political and economic climate. They complement and support the more general efforts of the European Physical Society and other bodies to bring together physicists from different countries.

The main goals of the bilateral cooperation agreements are:

- To facilitate scientific contacts between individual physicists and physics institutions from both countries;

- To promote the regular exchange of scientific literature and of information about scientific meetings, physics education at all levels, career opportunities, etc.;

- To make available physics journals published by a national society to members of another society by offering special discounts: - To encourage the exchange of physicists.

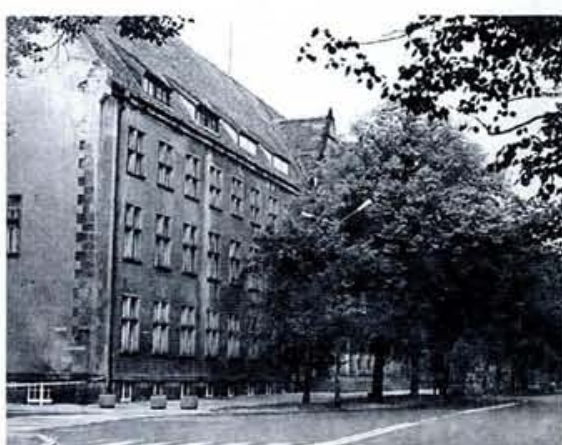

The 33rd Congress of the Polish Physical Society took place in Wroclaw Technical University's Institute of Physics.

years ago. The region now sees itself as being once more at a strategic cross-road in Europe, where user facilities such as the international high magnetic laboratory have a natural home.

expensive. For instance, an agreement typically calls for the two societies to arrange for financial support enabling the participation of physicists, notably those under 30 years old, from one country in conferences, symposia, specialized seminars, summer schools, and suchlike in the other country. Hence, the sending side often aims to meet the return fares of its own physicists while the receiving side defrays the costs of accommodation and living expenses of incoming visitors, as well as travel within the country necessitated by the scientific programme. Economic constraints oblige poor societies such as the PPS to limit the number of agreements and/ or their scope. This tends to imply drastically reduced opportunities for exchange.

At present, the Polish Physical Society has cooperation agreements with The American Physical Society, The Institute of Physics (UK), the Physical Section of the Union of Czech Mathematicians and Physicists, and the Ukrainian Physical Society. Agreements with German Physical Society and with the Slovak Physical Society will be signed shortly, and negotiations with The Japan Physical Society have started.
It is clear that the agreements provide a direct and rapid flow of information between the two partners, something that is especially valuable when the societies have to solve similar problems. On the other hand, it must be emphasized that realising all the obligations connected with the agreements can be

\section{INTERNATIONAL USER FACILITIES}

\section{Wroclaw's High Fields at Low Temperatures}

It is often overlooked that there exist in east and central Europe several truly international user facilities. A case in point is the International Laboratory of High Magnetic Fields and Low Temperatures in Wroclaw (IL for short). It was spun off from the Polish Academy of Sciences' Institute for Low Temperatures and Structural Research (INTiBS) in 1968 by an agreement between the Academies of Sciences of Bulgaria, the former German Democratic Republic, Poland and the former Soviet Union (FSU). INTiBS itself was founded in 1966, essentially following the merger of groups created in the late-1950s by scientists that moved from Illov when the position of the Polish-Ukrainian border changed at the end of World War II.

The successors to the various academies re-established themselves as the IL's main partners in 1992, and were joined in 1994 by four Associate Members (the National Academy of Ukraine and physics institutes in Cologne, Dresden and Moldavia). The IL, with a staff of 55 , now operates under the umbrella of the INTiBS that maintains departments for physical chemistry, metals and magnetism, and superconductivity and low temperatures based on a staff of about 230 . J. Klamut, the IL Director, served as the Director of INTiBS until J.Z. Sznajd took over in 1993.

The IL currently provides some 200 person-weeks of facility time to visiting users. The facilities comprise several conventional and superconducting steady-state high-field magnet systems and a $45 \mathrm{~T} / 10^{-35} \mathrm{~ms}$ pulsed field magnet. The laboratory is especially proud of its facilities for low-temperature $(10 \mathrm{mK})$ property measurements at high field $(16 \mathrm{~T})$. Its original, essentially political, concept was based on the Soviet Union meeting half the cost of an international laboratory that would then find it easier to attract support. The IL now has a more scientific basis, with Poland aiming to cover infrastructure and running costs and the other mem- 